\title{
Regulatory Roles of miRNA in the Human Neural Stem Cell Transformation to Glioma Stem Cells
}

\author{
Shuang Liu, ${ }^{1 *}$ Feng Yin, ${ }^{1,+}$ Jianning Zhang, ${ }^{1}$ Max S. Wicha, ${ }^{2}$ Alfred E. Chang, ${ }^{2}$ \\ Wenhong Fan, ${ }^{3}$ Ling Chen, ${ }^{4}$ Ming Fan, ${ }^{3 *}$ and Qiao $\mathrm{Li}^{2 *}$ \\ ${ }^{1}$ Department of Neurosurgery, Navy General Hospital PLA, Beijing 100048, China \\ ${ }^{2}$ University of Michigan Medical School, Ann Arbor, Michigan 48109, USA \\ ${ }^{3}$ Department of Brain Protection \& Plasticity Research, Beijing Institute of Basic Medical Sciences, Beijing 100850, \\ China \\ ${ }^{4}$ Department of Neurosurgery, Chinese PLA (People’s Liberation Army) General Hospital, Beijing 100853, China
}

\begin{abstract}
To investigate the expressional alternation of microRNAs (miRNA) during the malignant transformation and development of human glioma, we measured miRNA expression profile as well as mRNA expression profile in normal human neural stem cells (hNSCs) and human glioma stem cells (hGSCs). We found 116 miRNA up-regulated and 62 miRNA down-regulated in GSCs. On the other hand, we identified 1,372 mRNA down-regulated, and 1,501 mRNA up-regulated in GSCs compared to those in NSCs. We then analyzed the pathways and the predicted target genes of the miRNAs which differ significantly in expression between GSCs and NSCs using the statistical enrichment methods. These target mRNAs are involved in many cancer-related signaling pathways, such as cell cycle, axon guidance, glioma development, adhesion junction, MAPK and Wnt signaling. Furthermore, we obtained the differently expressed miRNA-target relationships according to the $\theta$ value which is used to calculate the regulation extent of miRNA-target and using the databases of miRanda, Targetscans and Pictar. Among the top 10 miRNA-target relationships, hsa-miR-198 and its potential targeted gene DCX and NNAT were selected for validation, and NNAT was found to be the direct target of miR-198. Finally, the functional roles of miR-155-5p and miR-124-3p whose expressions altered significantly between GSCs and NSCs were addressed. Our results provide new clues for the potential mechanisms involved in the origin and development of glioma. Clinically, the altered miRNAs may serve as potential targets and diagnostic tools for novel therapeutic strategies of glioblastoma. J. Cell. Biochem. 115: 1368-1380, 2014. @ 2014 Wiley Periodicals, Inc.
\end{abstract}

KEY WORDS: microRNA; MICROARRAY; REGULATORY NETWORK; HUMAN GLIOMA STEM CELLS; HUMAN NEURAL STEM CELLS

$\mathrm{M}$ alignant gliomas are the most common and deadly primary brain tumors in adults [Maher et al., 2001]. Although there is much progress in surgery, radiotherapy and chemotherapy for the management of this disease, the prognosis of malignant glioma is still poor. The median survival time for glioblastoma (GBM) is
14 months [Maher et al., 2001]. The indistinct knowledge about the origin of glioma limits the technique development for their therapy. Recent studies of human brain tumors have shown that there is a small group of cell types that have the ability to regenerate themselves and are resistant to radiotherapy and chemotherapy.

Abbreviations: GBM, glioblastom; miRNA, microRNA; qRT-PCR, real time quantitative RT-PCR; BTSC, brain tumor stem cells; GSCs, glioma stem cells; NSCs, neural stem cells; MAPK, mitogen-activated protein kinase; 3'-UTR, 3' untranslated region; FC, fold change; Sox 1, SRY(Sex determining region Y)-box 1; GAD2, Glutamate decarboxylase 2; NNMT, Nicotinamide N-methyltransferase.

${ }^{\dagger}$ Co-first author.

CONFLICT OF INTEREST DISCLOSURE: None authors has any conflict of interest.

Grant sponsor: National Nature Science Foundation of China; Grant numbers: 81172384, 30873029, 81272804; Grant sponsor: Gillson Longenbaugh Foundation.

*Correspondence to: Shuang Liu, Institute of Neurosurgery, Navy General Hospital of PLA, Beijing, 100048, China. E-mail: shuangff@sina.com; Ming Fan, Department of Brain Protection \& Plasticity Research, Beijing Institute of Basic Medical Sciences. Beijing 100850. E-mail: fanmingchina@126.com; Qiao Li, University of Michigan Medical School, 1150 West Medical Center Drive, 3520MSRB-1, Ann Arbor, Michigan 48109. E-mail: qiaoli@umich.edu

Manuscript Received: 31 March 2013; Manuscript Accepted: 30 April 2013

Accepted manuscript online in Wiley Online Library (wileyonlinelibrary.com): 12 February 2014

DOI 10.1002/jcb.24786 • (c) 2014 Wiley Periodicals, Inc. 
These cells are brain tumor stem cell (BTSC) enriched [Singh et al., 2004; Galli et al., 2004; Dean et al., 2005; Rich et al., 2007]. The BTSCs have shown many characteristics in common with neural stem cells (NSCs), such as self-renewal and multi-potential differentiation. It was supposed that BTSCs might originate from mutant NSCs [Calabrese et al., 2007; Quinones et al., 2007; Chaichana et al., 2009]. Elucidating the genetic circuits that govern the malignant transformation from NSCs to GSCs is essential to understanding the origin of brain tumors and to the development of novel therapeutic strategies for malignant glioma. Extensive efforts have been made to determine such regulatory circuits through the profiling of messenger RNA (mRNA) in glioma tissues [Pragathi et al., 2010; Dinorah et al., 2012; Katz et al., 2012; Leone et al., 2012]. However, since mRNA profiles largely reflect the consequences of transcriptional regulation, these studies do not fully take into account the extensive post-transcriptional programs that control the NSC malignant transformation and the glioma origin, particularly those programs that are controlled by an abundant class of noncoding RNAs, the microRNAs (miRNAs).

MiRNAs are a species of small, noncoding, single-stranded RNA molecules (19-22 nucleotides) that repress translation or initiate transcript degradation by imperfect base pairing with cognate target mRNAs [Bartel et al., 2009]. In sum, more than half of the human protein-coding genes appear to have been under selective pressure to maintain 3'-UTR pairing to miRNAs [Friedman et al., 2008]. Each miRNA can potentially regulate several hundred-target genes [Bartel et al., 2009; Friedman et al., 2009]. Thus, miRNA-mediated gene regulation may have profound effects on gene expression. They are implicated in several biological processes, including development, proliferation, differentiation, apoptosis, and pathogenesis of cancer cells [Bartel et al., 2004; Berezikov et al., 2005; Hwang et al., 2006]. Different miRNAs may function as either tumor suppressors or oncogenes, and the deregulation of their expression is associated with the initiation and progression of cancer [Croce et al., 2009]. While the origin of gliomas is largely unknown, there is increasing speculation that they may arise from glioma stem cells (GSCs) that are transformed from NSCs [Calabrese et al., 2007; Quinones et al., 2007; Chaichana et al., 2009]. Several recent studies have revealed that miRNA regulates various aspects of GSCs biology [Zhu et al., 2005; Kesari et al., 2006; Piccirillo et al., 2006; Sherry et al., 2009; Chan et al., 2012; Ying et al., 2012]. However, few studies have been carried out to clarify the regulatory roles of miRNA in the malignant transition of NSCs to BTSCs, or GSCs.

In this study we conducted a genome-wide miRNA expression study (1665 human microRNA probes) and mRNA expression study $(29,186$ human mRNA probes) in normal NSCs and adult GSCs to ensure a broad profiling among cellular miRNAs and mRNAs. Then, we investigated the miRNA programs that may mark the transition of NSCs to GSCs and identified several key pathways involved in this transition.

\section{MATERIALS AND METHODS}

\section{HUMAN NSC ISOLATION AND PRIMARY CULTURE}

Human NSCs were obtained from the hippocampus of three 12-week male fetuses of spontaneous abortion. They were cultured in vitro by the procedures that were previously described [Liu et al., 2009]. Briefly, the dissociated cells were put into culture plates with serumfree medium supplemented with mitogens $(20 \mathrm{ng} / \mathrm{ml}$ EGF, $20 \mathrm{ng} / \mathrm{ml}$ b-FGF, and $10 \mathrm{ng} / \mathrm{ml}$ LIF) (Invitrogen, CA, USA). After 7 days, the formation of neurospheres was observed with a phase-contrast microscope.

\section{ISOLATION AND CULTURE OF HUMAN GSCs}

Human GSCs were isolated from three glioblastoma specimens of male patients. Briefly, tumor nodules were minced and digested by $0.5 \%$ trypsin at $37^{\circ} \mathrm{C}$ for $15 \mathrm{~min}$. After filtration through $70 \mu \mathrm{m}$ mesh, the dispersed cancer cells were collected by centrifugation and then cultured in the same medium as that used for hNSCs above. The culture media were changed every 3 days. Tumor spheres of different passages were dissociated into single cells which were then plated one cell per well. The formation of tumor spheres was observed with a phase-contrast microscope.

\section{ETHICS STATEMENT}

We obtained consents from all participating patients who were informed and knew the purpose and risk of taking specimens. This study has been approved by the Medical Ethics Committee of Navy General Hospital, PLA, Beijing, China. This study was also performed in strict accordance with the recommendations in the Guide for the Care and Use of Laboratory Animals of the Chinese Institutes of Health. The protocol was approved by the Committee on the Ethics of Animal Experiments of Navy General Hospital (Permit Number: 0308-2013). All surgery was performed under sodium pentobarbital anesthesia, and every effort was made to minimize suffering.

\section{IMMUNOFLUORESENCE STAINING TO DETECT THE EXPRESSIONS OF CD133 AND DIFFERENTIATION MARKERS OF THE GSCS}

To characterize the hGSCs, the tumor spheres were transferred to poly-D-lysine coated chamber slides and cultured in differential medium of NSCs (DMEM-F12 supplemented with 10\% FBS) for differentiation [Liu et al., 2009]. After 1 and 10-day differentiation, cells grown on the slides were fixed with $4 \%$ paraformaldehyde in PBS at room temperature for $30 \mathrm{~min}$, and permeabilized with $0.1 \%$ Triton X-100 for immunofluorescence staining. The slides were probed with mouse antibodies against human CD133 (1:1000, Santa Cruz, CA, USA), human $\beta$-Tubulin-III (1:1000, Santa Cruz, CA, USA) and goat antibody against GFAP (1:1000, BD Bio-science, NY, USA), at $4{ }^{\circ} \mathrm{C}$, overnight. The secondary antibodies were either FITC- or RBITC conjugated anti-mouse IgG and anti-goat IgG (1:1000, Santa Cruz, CA, USA), at room temperature for $30 \mathrm{~min}$. The cells were then counterstained with $4^{\prime}, 6^{\prime}$-diamidino-2-phenylindole (DAPI; Santa Cruz, CA, USA). Images were captured by a laser scanning confocal microscope (Olympus, Tokyo, Japan).

\section{EXAMINATION OF TUMORIGENICITY OF THE GSCS}

To establish intracranial tumors, $1 \times 10^{5}$ cells from the GSC spheres were implanted into the brains of adult female nude mice by procedures that were previously described [Liu et al., 2012]. Briefly, under the guidance of a stereotactic system, $4 \mu \mathrm{l}$ cell suspension were delivered into the right caudate nucleus $(2 \mathrm{~mm}$ lateral and $1 \mathrm{~mm}$ anterior to bregma; depth $2.5 \mathrm{~mm}$ from dura, $0.2 \mu \mathrm{l} / \mathrm{min}$ ) by injection 
through a glass electrode connected to a Hamilton syringe. Nude mice were sacrificed when they became moribund or showed signs of obvious neurological deficit. The frozen sections $(10 \mu \mathrm{m})$ of the tumors were examined under a fluorescence microscope. The athymic Balb/c nude mice (female), which weigh from 20 to $25 \mathrm{~g}$, were phased from the Animal Center of the Chinese Academy of Medical Science. The mice were maintained in laminar flow cabinets under pathogen-free conditions and were handled according to the policies and standards of Laboratory Animal Care in China.

\section{microRNA MICROARRAY}

Fluorescent targets were prepared from $2.5 \mu \mathrm{g}$ of total RNA samples (3 GSCs and 3 NSCs) using miRNA ULSTM Labeling Kit (Kreatech Diagnostics, The Netherlands). Labeled miRNA targets that were enriched by NanoSep $100 \mathrm{~K}$ (Pall Corporation, USA) were hybridized to the Human miRNA OneArray ${ }^{\mathbb{R}}$ v4.0 (HmiOA v4.0 from Phalanx Biotech Group, Xinzhu, Taiwan) with Phalanx hybridization buffer using OneArray ${ }^{\mathbb{R}}$ Hybridization Chamber. After $16 \mathrm{~h}$ of hybridization at $37^{\circ} \mathrm{C}$, non-specific binding targets were washed away by three different washing steps (Wash I $37^{\circ} \mathrm{C} 5 \mathrm{~min}$; Wash II $37^{\circ} \mathrm{C}, 5 \mathrm{~min}$; Wash III $25^{\circ} \mathrm{C}, 5 \mathrm{~min}$ ). The slides were then dried by centrifugation and scanned by an Axon 4000B scanner (Molecular Devices, Sunnyvale, CA, USA). The Cy5 fluorescent intensities of each spot were analyzed by GenePix 4.0 software (Molecular Devices).

The signal intensity of each spot was processed by the R program. We filtered out spots which the flag $<0$. Spots that passed the criteria were normalized by the $75 \%$ media scaling normalization method. Normalized spot intensities were transformed to gene expression $\log 2$ ratios of the control and treatment groups. We have submitted the data of microRNA array to GEO. The GEO accession number is GSE 41033 (miRNA profiles of brain glioma stem cells and normal neural stem cells).

\section{HYBRIDIZATION ON HUMAN HOA5.1 ONEARRAY}

Cells (3 GSCs and 3 NSCs) were lysed and total RNA was extracted by RNeasy Midi kit (Qiagen, Valencia, CA) according to the manufacturer's instructions. The RNA's integrity and purity were checked by the electrophoresis of total RNA (Fig. S-1). Then we performed mRNA expression profiling detection using the Human HOA5.1 OneArray (Phalanx Biotech Group, Xinzhu, Taiwan) for three times. Data was collected and analyzed on the Rosetta Resolved System (Rosetta Biosoftware, WA, USA). A differentially expressed gene list was generated by standard selection criteria as established by |Fold Changel $\geq 2$ or $\leq 0.5$, and $P<0.01$. We have submitted the data of mRNA array to GEO, and the GEO accession number is GSE 41031 (Transciptome profiles of brain glioma stem cells and normal neural stem cells).

\section{VERIFICATION OF MICROARRAY DATA WITH qRT-PCR}

Total RNA was isolated from cultured GSCs and NSCs using Trizol reagent (Invitrogen), according to the manufacturer's instructions, and assayed by real-time RT-PCR. All primers were designed according to miRNA and mRNA sequences. A universal PCR reverse primer was designed using Primer Express version 5.0 (Applied Biosystems, Foster City, CA) [Chen et al., 2005]. U6small nuclear RNA gene was used as an internal control [Schmittgen et al., 2004], and oligonucleotide primers were shown in Table S-1. Real-time quantitative PCR was performed using standard protocols on an Applied Biosystem's 7900HT Sequence Detection System. Briefly, $5 \mu \mathrm{l}$ of template cDNA in water was added to $12.5 \mu \mathrm{l}$ of the $2 \times \mathrm{SYBR}$ green PCR master mix (Applied Biosystems), and then $2 \mathrm{mM} \mathrm{MgCl}$, $0.5 \mu \mathrm{M}$ of each primer and water were added to $25 \mu$ l of the $2 \times$ SYBR green PCR master mix. The procedures were conducted using Light Cycler PCR 1.2 (Roche), and Light Cycler FastStart DNA Master SYBR Green I(Roche). The amplification of selected genes was carried out as follows: a 3-min hot start at $97^{\circ} \mathrm{C}$ followed by 40 cycles of denaturation at $95^{\circ} \mathrm{C}$ for $30 \mathrm{~s}$, annealing at $56^{\circ} \mathrm{C}$ for $20 \mathrm{~s}$, and a $72^{\circ} \mathrm{C}$ extension for $30 \mathrm{~s}$. Melting curves were acquired at $75-95^{\circ} \mathrm{C}$, and samples were also run on a $3 \%$ agarose gel to confirm the specificity. Each time point included three individual samples in triplicate. Each assay included a negative control (water instead of template cDNA). The experiment was done in duplicate.

\section{DATA ANALYSIS OF microRNA AND mRNA}

The microRNA expression profiling, including data filtering, normalization and statistical calculations, was processed by Robust Multichip Average (RMA)./R version 2.12.1. The mRNA arrayslides were scanned immediately by an Axon 4000B dual channel scanner (Axon lnstruments, Foster City, CA). The data analysis of gene expression profiling, including data filtering, normalization and statistical calculations, was processed by Rosetta Resolver ${ }^{\circledR}$ System (Rosetta Biosoftware, WA, USA). The Rosetta Resolver ${ }^{\mathbb{R}}$ error model provides a judgment of the probe signal's credibility. Both miRNA and mRNA Arrays of any compared sample set are normalized after filtering probes according to the flag note from the gpr files.

\section{BIOINFORMATICS ANALYSIS AND TARGET PREDICTION}

Three online software programs, miRanda http://microrna.sanger. ac.uk, picTar http://www.ncma.org/knowledgeBase/link-database/ mirna target database and targetscan http://www.targetscan.org, were used for bioinformatics analysis and target prediction for the miRNAs. We then identified more reliable miRNA-target relationships using the Pearson analysis and Fisher method. The enrichment analysis of GO and the KEGG pathway was conducted to study the regulatory effects of targeted microRNAs. In addition, all the human genes that have GO annotation were used as background genes, and the query genes were those differentially expressed genes that had GO annotation.

\section{TRANSFECTION OF microRNAs MIMICS AND THE USE OF microRNAs INHIBITORS}

We selected hsa-miR-198 for target gene validation, miR-155-5p and miR-124-3p for functional analysis. MiR-198 inhibitor, miR155-5p inhibitor, miR-124-3p mimic and negative controls were designed and synthesized by GenePharma (Shanghai, China). Cells were transfected using Lipofectamine 2000 reagent (Invitrogen, CA, USA). The final concentrations of miRNA inhibitors, miRNA mimics and negative controls were $50 \mathrm{nM}$.

\section{PROTEIN EXTRACTION AND WESTERN BLOT ANALYSIS}

Total protein was extracted by using NP40 lysis buffer (0.5\% NP40, $250 \mathrm{mM} \mathrm{Nacl}, 50 \mathrm{mM}$ HEPES, $5 \mathrm{mM}$ ethylenediamine tetraacetic 
acid, $0.5 \mathrm{mM}$ egtazic acid) supplemented with protease inhibitor cocktails (Sigma, MO, USA). Standard western blotting was undertaken with monoclonal antibodies against human DCX, NNAT, GFAP and $\beta$-actin proteins (Santa Cruz Biotechnology, CA, USA) and the corresponding secondary antibodies (Abcam, Camb, UK). Human $\beta$-actin was used as a loading control.

\section{LUCIFERASE ASSAY AND VECTOR CONSTRUCTION}

For the luciferase assay, the region predicted to harbor interactor sites (298-305 bp) of NNAT 3'-UTR (NM_181689) were amplified by PCR from human genomic DNA and inserted into the pGL3 control vector (wild-type) (Promega, WI, USA). GSCs were plated in 96-well dishes at $10^{4}$ cells/well. Then cells were cotransfected with miR-198 mimic and pGL3 NNAT 3'-UTR constructs or scrambled with mutant pGL3 NNAT 3'-UTR constructs. Forty-eight hours after transfection, cells were incubated for $10 \mathrm{~min}$ with $20 \mu \mathrm{L} /$ well $1 \times$ Passive Lysis Buffer (Promega, WI, USA). Firefly and renilla luciferase activities were measured sequentially using dual luciferase assays (Promega) by a Veritas microplate luminometer (Turner BioSystems, Sunnyvale, CA). The experiments were performed in quadruplicate in three independent sets. Values are shown as mean $\pm \mathrm{SD}$.

\section{FUNCTIONAL ANALYSIS FOR HSA-MIR-155-5P AND MIR-124-3P}

MiR-155-5p inhibitor and miR-124-3p mimic were used to inhibit the expression of miR-155-5p and rescue the expression of miR124-3p in GSCs respectively. MiR-155-5p inhibitor, miR-124-3p mimics and negative controls were designed and synthesized by GenePharma (Shanghai, China). Cells were transfected using Lipofectamine 2000 reagent (Invitrogen, CA, USA). The final concentrations of miR-155-5p inhibitor, miR-124-3p mimic and negative controls were $50 \mathrm{nM}$. For GSCs differentiation, the medium was replaced with a fresh neural differentiation medium (10\% fetal bovine serum (Gibco, MI, USA) $4 \mathrm{~h}$ after treatment. $48 \mathrm{~h}$ after treatment qRT-PCR was performed to identify the altered expressions of miR-155-5p and miR-124-3p. Then, a CCK-8 assay, GFAP immunoblotting assay and Annexin $\mathrm{V}$ staining were undertaken to study the effects of miR-155-5p and miR-124-3p on GSCs.

For the CCK- 8 assay, $2 \times 10^{3}$ GSCs per well were placed onto a 96-well plate. Then, the cells were transfected with miR-155-5p inhibitor or miR-124-3p mimic and negative controls for $1 \mathrm{~h}$ and further cultured in the chamber for 24, 48 and $72 \mathrm{~h}$. CCK-8 reagent was added to the cells $2 \mathrm{~h}$ before measuring the optical density (OD) of $450 \mathrm{~nm}$ by a microplate reader according to the manufacturer's instructions. Apoptosis was measured in GSCs $48 \mathrm{~h}$ after transfection by means of Annexin $\mathrm{V}$ immunostaining and flow cytometry analysis using the Annexin V-FITC detection kit (BD PharMingen, San Diego, CA, USA).

\section{RESULTS}

\section{ISOLATION AND CHARACTERIZATION OF GSCs}

Human GSCs were isolated and cultured as described in the Materials and Methods. After 1 week of primary culture, we obtained tumor spheres from the GSCs isolated from the GBM tissues (Fig. 1A). These tumor spheres could be expanded for 10 passages in vitro. Most of the cells in the tumor spheres are CD133 positive (Fig. 1B). When these cells were differentiated, GFAP positive astrocytes and $\beta$-tubulin positive neurons could be detected, though the morphology of them still remains immature (Fig. 1C). After being implanted intracranially, these cells could form brain tumors (Fig. 1D). Together, these data indicate that the CD133 positive cells in the tumorspheres are GSC-enriched.

\section{DIFFERENTIAL EXPRESSION OF microRNAs AND GENES IN GSCs VERSUS NSCS}

To identify the microRNA programs that may mark the critical transition of NSCs to GSCs, we compared the microRNA and mRNA expression profiles of GSCs and NSCs using a normalization factor and clustering. The FC is the ratio of the expression average of case groups to the expression average of control groups. A microRNA was defined as differentially expressed when a fold change (FC) $\geq 1.5$ or less than $1 / 1.5$, and a value of $P<0.05$ was obtained. We found that 116 microRNAs were up-regulated and 62 microRNAs were downregulated in GSCs compared to NSCs. The top 10 up-regulated microRNAs and top 10 down-regulated microRNAs are shown in Table I (The expression values of these microRNAs were shown in Table S-2). Among them, the FC value of miR-155-5p in GSCs is $>9$ times higher than that in NSCs. In contrast, the FC value of miR124-3p in GSCs is $<1 / 60$ of that in NSCs. Both have been shown to play important roles in the development of tumors (Lang et al., 2012; Silber et al., 2013). MicroRNA hierarchical clustering was generated for both up-regulated and down-regulated miRNAs with foldchanges greater than 1.5 or less than $1 / 1.5$. The hierarchical clustering image of miRNAs is shown in Figure S-2. In contrast to NSCs, we found 1501 genes up-regulated, and 1372 genes downregulated in GSCs based on the selection criteria that FC $>2$ or $\mathrm{FC}<1 / 2$, and a value of $P<0.01$. We showed the top 10 of differentially expressed genes in GSCs in Table II (The expression values of these genes were shown in Table S-2). A subset of differentially expressed genes was selected for clustering analysis. For this microarray project, the number of genes clustered was 2873. The hierarchical clustering image of the genes is shown in Figure S-3.

Using G0 enrichment analysis carried out on the ranked list of mRNAs, we were able to elucidate the biological modules that are correlated or anti-correlated to the expression level of the pivot miRNA. This association indicates the biological process in which the pivot miRNA plays a role. According to the analysis of GO and KEGG pathways, several pivot miRNAs showed a strong association with the development of glioma, such as axon guidance, cell cycle, cell adherence and apoptosis et al. (Fig. 2).

\section{SCREENING THE RELATIONSHIPS OF microRNAs AND TARGETS}

To further examine the function of those significantly altered miRNAs (116 up-regulated and 62 down-regulated) in GSCs compared with NSCs, we proceeded to searching the target genes of miRNAs associated with GSCs. Based on the differential expressions of miRNAs and mRNA targets as described above, we analyzed the relationships of miRNA-targets using the databases of miRanda, Targetscans and Pictar. We found 947 relationships, 

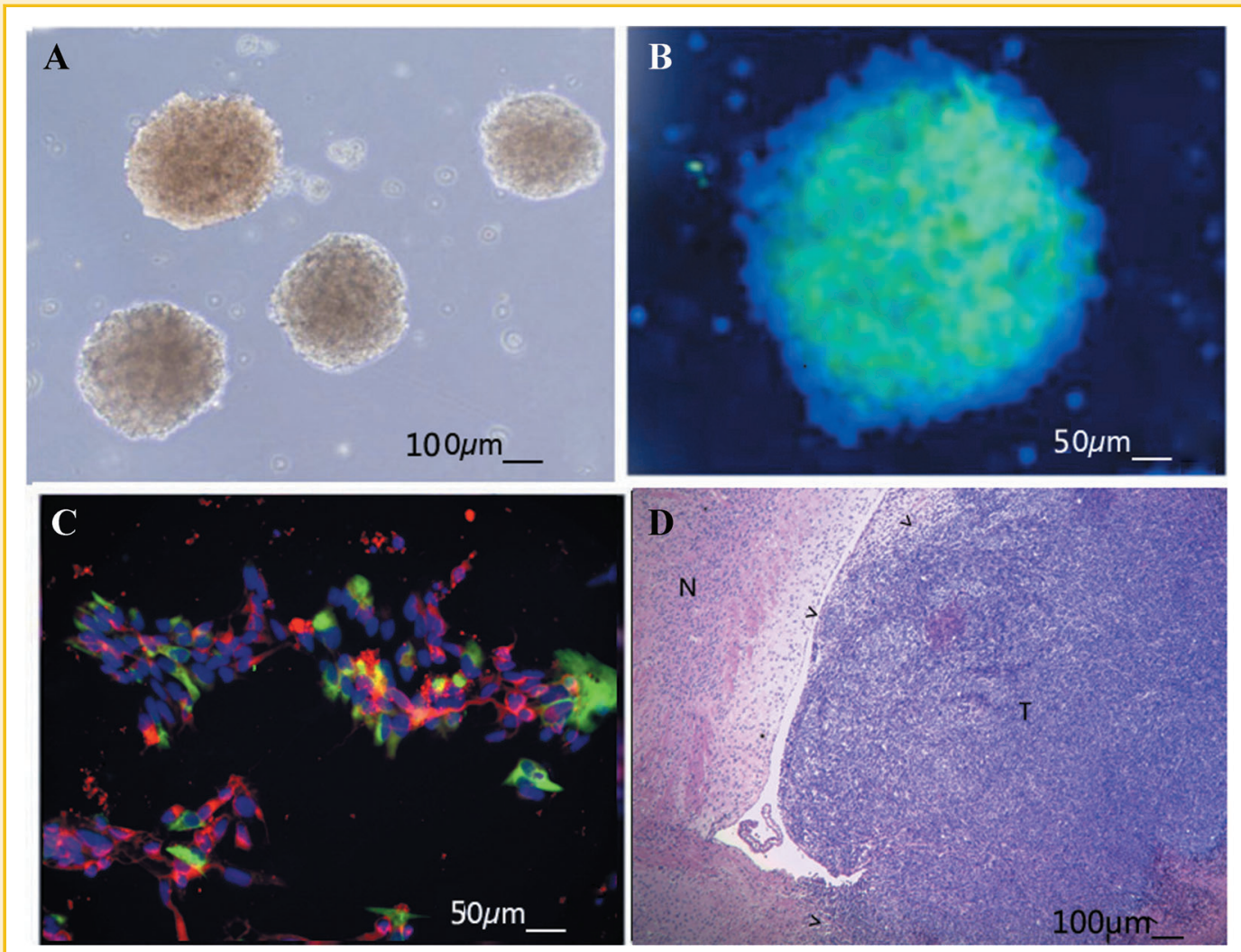

Fig. 1. Characterization of hGSCs. A) After culture in vitro for 7 days, hGSCs formed neurosphere (20x). B) The spheres of GSCs were transferred to poly-D-lysine coated chamber slides and cultured in DMEM-F12 supplemented with 10\% FBS. After $24 \mathrm{~h}$ of culture, the tumor spheres were stained with mouse antibody against human CD133. Most of the tumor cells in the sphere were CD133 positive (Green) $(40 \times)$. C) After differentiation, the slides were probed with goat antibody against human GFAP and mouse antibody against human $\beta$-Tubulin. GFAP immunoreactive positive astrocytes (Red) and $\beta$-Tubulin immunoreactive positive neurons (Green) were observed ( $40 \times$ ). D) $1 \times 10^{5}$ tumor cells from the GSC spheres were implanted into the brains of adult female nude mice by a stereotactic system. One month later, HE staining showed that the GSCs formed neoplasm $(40 \times)$. In the picture, tumor margin was indicated by " $>$ ", and the tumor tissue was indicated by "T", while normal brain tissue was indicated by " $\mathrm{N}$. The above experiments were repeated three times respectively.

involving 29 miRNAs and 844 protein-coding genes (Table S-3). Among them, the relationships of hsa-miR-1-GNPDA2 and hsamiR-1-CLCN3 have been clarified [Lim et al., 2005; Goljanek et al., 2012]. We calculated the regulation extent of the miRNA-target using $\theta$ value. The formula is $\theta=(|\mathrm{FC} 1-1 / \mathrm{FC} 2|)$ (FC1: up-regulated gene or microRNA, FC2: thedown-regulated microRNA or gene, which is relative to the up-regulated genes and microRNA). Using the $\theta$ values, we obtained the top 10 differently expressed miRNA-target relationships, which are shown in Table III.

\section{REAL-TIME RT-PCR OF microRNAs AND GENES}

To confirm the identification of these differentially expressed microRNAs and genes, we used real-time RT-PCR to detect the expression levels of six microRNAs (hsa-miR-198, hsa-miR-137, hsa-miR-653, hsa-miR-146b-5p, hsa-miR-152, and hsa-miR-125a3p) and seven target genes of these miRNAs (DCX, PTGS2, SCGN, GAD2, OTX2, PEG10, and NRXN3), which were found to have significant inverse correlation (Table III). All primers were designed based on miRNA and mRNA sequences. U6 small nuclear RNA gene and $\beta$-actin gene were used as internal controls. The $\mathrm{Ct}$ value is the fractional cycle number at which the fluorescence generated by the reporter dye exceeds a fixed level above the baseline. The selected genes' signals were normalized against the relative quantity of U6 and expressed as $\Delta \mathrm{Ct}=$ (Ct selected gene $-\mathrm{Ct} \mathrm{U} 6)$. The change in selected genes' signals relative to the reference signal (control sample) was expressed as $\Delta \Delta \mathrm{Ct}=(\Delta \mathrm{Ct}$ control $-\Delta \mathrm{Ct}$ sample). The relative changes in expression were then calculated as $2^{[-\Delta \Delta \mathrm{Ct}]}$. Five of the six selected microRNAs and all of the seven selected genes were differentially expressed between the hNSCs and hGSCs analyzed in this study, and concordant with the microarray data, with miR-653 being the only exception (Table S-4). The amplification curves and melting curves in the PCR reactions and the statistic bar charts are shown in Figure 3. As shown in Figure 3C, the concordance rate of miRNA array and qRT-PCR is $83.33 \%$, and the concordance rate of mRNA and qRT-PCR is 100\% (Figure 3F).

\section{VALIDATION OF DIRECT TARGET OF MIR-198}

Among the top 10 differently expressed microRNA-target relationships (Table III), we selected miR-198 and its predicted targets (DCX and NNAT) to validate. We analyzed the expression alterations of 
TABLE I. The Top 10 Up-Regulated and Top 10 Down-Regulated microRNAs in GSCs

\begin{tabular}{|c|c|c|c|c|}
\hline & microRNA & FC & $P$-value & $q$-value \\
\hline \multirow[t]{11}{*}{ Up-regulated microRNAs } & hsa-miR-155-5p & 9.46093 & 0.002279 & 0.107965 \\
\hline & hsa-miR-1247-3p & 6.910358 & 0.009639 & 0.167936 \\
\hline & hsa-miR-513a-5p & 6.589985 & 0.01189 & 0.177153 \\
\hline & hsa-miR-4299 & 6.06227 & 0.000807 & 0.086871 \\
\hline & hsa-miR-513b & 5.9837 & 0.004612 & 0.126887 \\
\hline & hsa-miR-4653-3p & 5.969425 & $4.38 \mathrm{E}-03$ & 0.126134 \\
\hline & hsa-miR-652-5p & 5.909472 & 0.001623 & 0.107754 \\
\hline & hsa-miR-642a-3p & 5.822695 & 0.001824 & 0.107754 \\
\hline & hsa-miR-30c-1-3p & 5.745478 & 0.005078 & 0.127089 \\
\hline & hsa-miR-1275 & 5.565442 & $6.62 \mathrm{E}-06$ & 0.006854 \\
\hline & hsa-miR-124-3p & 0.016607 & 0.003935 & 0.125472 \\
\hline \multirow{9}{*}{ Down-regulated microRNAs } & hsa-miR-7-5p & 0.206311 & 0.012752 & 0.178109 \\
\hline & hsa-miR-3148 & 0.315938 & 0.005779 & 0.135649 \\
\hline & hsa-miR-135b-5p & 0.338157 & 0.005778 & 0.135649 \\
\hline & hsa-miR-3650 & 0.343757 & 0.015203 & 0.193413 \\
\hline & hsa-miR-181c-5p & 0.398294 & 0.008941 & 0.164242 \\
\hline & hsa-miR-153 & 0.404268 & 0.01983 & 0.216071 \\
\hline & hsa-miR-147a & 0.416814 & 0.000382 & 0.065449 \\
\hline & hsa-miR-128 & 0.418377 & 0.037754 & 0.276778 \\
\hline & hsa-miR-4999-5p & 0.440248 & 0.002895 & 0.107965 \\
\hline
\end{tabular}

A microRNA was defined as differentially expressed when fold change $(\mathrm{FC}) \geq 1.5$ or $\leq 1 / 1.5$, and a value of $\mathrm{p}<0.05$ was obtained. We found that 116 microRNAs were upregulated and 62 microRNAs were downregulated in GSCs compared to NSCs.

DCX and NNAT proteins by western blot $48 \mathrm{~h}$ after knocking-down of miR-198 in GSCs. Results showed that NNAT expression increased significantly after miR-198 knocking-down, but DCX did not change expressively (Fig. 4A). Furthermore, regulation of NNAT by miR-198 was confirmed by luciferase assay. The results showed that the reporter plasmid with wild-type $3^{\prime}$-UTR of NNAT caused a significant increase in luciferase activity in GSCs transfected with miR-198 inhibitor, whereas mut-type 3'-UTR of NNAT produced no change in luciferase activity (Fig.4B). Taken together, these data indicate that miR-198 directly modulates NNAT expression by binding to 3'UTR of NNAT.

\section{FUNCTION ANALYSIS FOR HSA-MIR-155-5P AND MIR-124-3P}

Hsa-miR-155-5p and miR-124-3p, which increased and decreased respectively most noticeably in GSCs compared to NSCs, were selected for functional analysis. To determine whether the abnormal

TABLE II. The Top 10 Up-Regulated and Top 10 Down-Regulated Genes in GSCs

\begin{tabular}{|c|c|c|c|c|c|}
\hline & Gene Symbol & Gene Description & $\mathrm{FC}$ & $P$-value & $q$-value \\
\hline \multirow[t]{11}{*}{ Up-regulated genes } & IGFBP3 & insulin-like growth factor binding protein 3 & 1354.4 & $1.54 \mathrm{E}-05$ & 0.00075 \\
\hline & PTGS2 & $\begin{array}{l}\text { prostaglandin-endoperoxide synthase } 2 \text { (prostaglandin } \mathrm{G} / \mathrm{H} \text { synthase } \\
\text { and cyclooxygenase) }\end{array}$ & 581.1269 & $1.28 \mathrm{E}-03$ & 0.006886 \\
\hline & NNMT & nicotinamide $\mathrm{N}$-methyltransferase & 451.7361 & $1.45 \mathrm{E}-06$ & $4.28 \mathrm{E}-04$ \\
\hline & PRORSD1P & prolyl-tRNA synthetase associated domain containing 1 , pseudogene & 385.9963 & $2.30 \mathrm{E}-06$ & 0.000439 \\
\hline & $\mathrm{CP}$ & ceruloplasmin (ferroxidase) & 166.5336 & 0.001636 & 0.00805 \\
\hline & CHI3L2 & chitinase 3 -like 2 & 165.5163 & $1.86 \mathrm{E}-04$ & 0.00231 \\
\hline & TNFAIP6 & tumor necrosis factor, alpha-induced protein 6 & 129.5437 & 0.002093 & 0.00947 \\
\hline & HOXB7 & homeobox B7 & 121.1777 & $1.39 \mathrm{E}-03$ & 0.007222 \\
\hline & CASP 4 & caspase 4 , apoptosis-related cysteine peptidase & 115.2229 & $1.24 \mathrm{E}-04$ & 0.001853 \\
\hline & BIRC3 & baculoviral IAP repeat containing 3 & 102.3944 & $5.35 \mathrm{E}-05$ & 0.00129 \\
\hline & NPY & neuropeptide Y & 0.000239 & 0.001885 & 0.008842 \\
\hline \multirow[t]{9}{*}{ Down-regulated genes } & SST & somatostatin & 0.001367 & $1.53 \mathrm{E}-06$ & 0.000428 \\
\hline & $\mathrm{DCX}$ & doublecortin & 0.001761 & $6.29 \mathrm{E}-07$ & 0.000306 \\
\hline & GAD2 & glutamate decarboxylase 2 (pancreatic islets and brain, $65 \mathrm{kDa}$ ) & 0.003766 & $1.99 \mathrm{E}-03$ & 0.009154 \\
\hline & INA & internexin neuronal intermediate filament protein, alpha & 0.004196 & $6.31 \mathrm{E}-07$ & 0.000306 \\
\hline & SLC32A1 & solute carrier family 32 (GABA vesicular transporter), member 1 & 0.004403 & 0.000254 & 0.00269 \\
\hline & SOX1 & SRY (sex determining region Y)-box 1 & 0.004933 & $2.51 \mathrm{E}-06$ & 0.00044 \\
\hline & MEG3 & maternally expressed 3 (non-protein coding) & 0.005550 & 0.000564 & 0.004202 \\
\hline & PEG 10 & paternally expressed 10 & 0.005780 & $6.74 \mathrm{E}-06$ & 0.000565 \\
\hline & NRXN3 & neurexin 3 & 0.006088 & $2.06 \mathrm{E}-05$ & 0.000848 \\
\hline
\end{tabular}

We found 1,501 genes up-regulated, and 1,372 genes down-regulated in GSCs based on the selection criteria that FC $>2$ or FC $<1 / 2$, and a value of $\mathrm{p}<0.01$." 


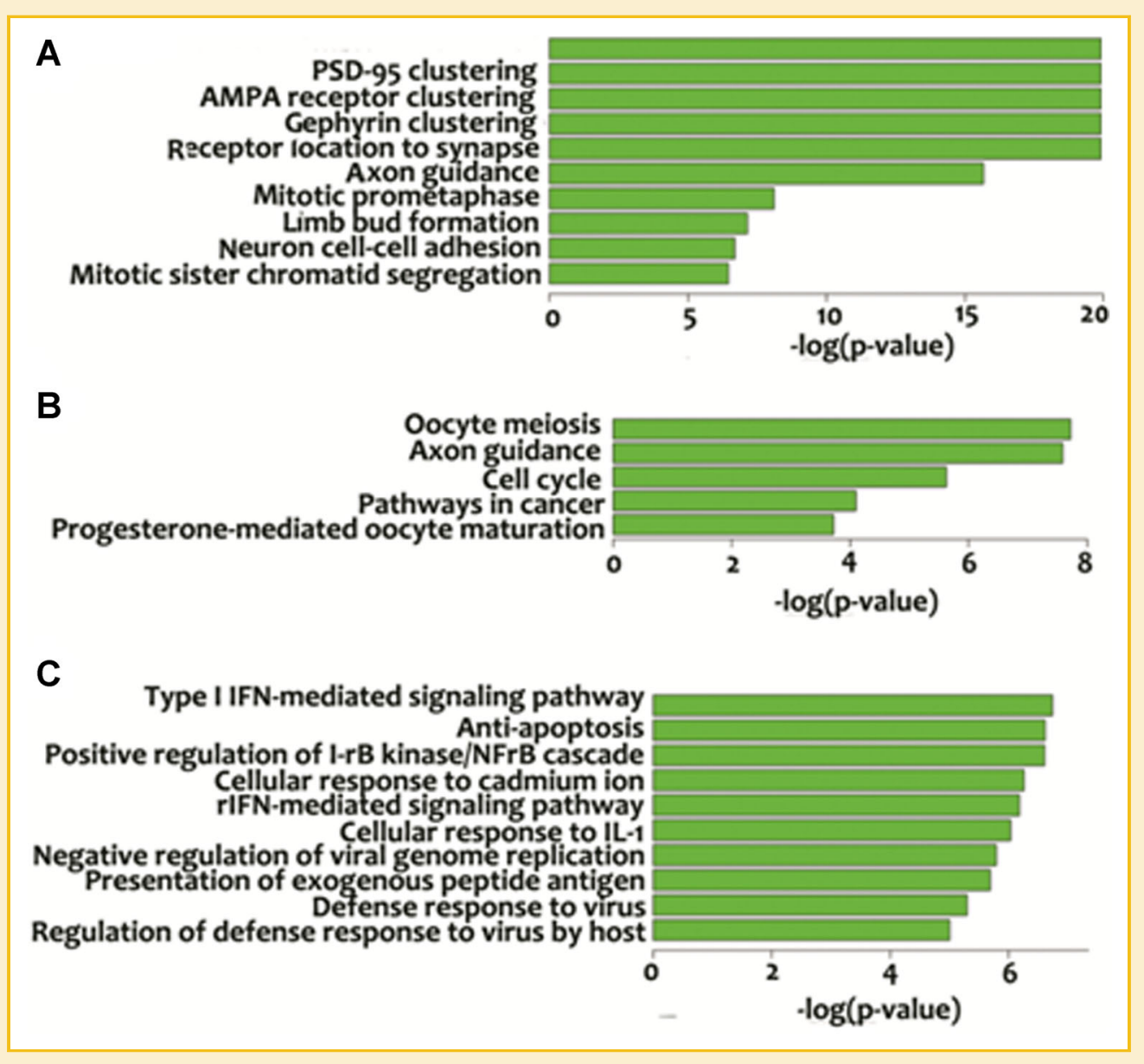

Fig. 2. Representative enriched GO BP and KEGG pathways of the down-regulated and up-regulated genes. A) The top 10 enriched GO BP of the down-regulated genes. Among the 1372 down-regulated genes, there are 139 enriched GO BP with FDR $<0.01$. The top 10 are shown. B) The relevant pathways of the down-regulated genes. In the downregulated genes, there are $5 \mathrm{KEGG}$ pathways with FDR $<0.01$. They are associated with oocyte meiosis, axon guidance, cell cycle, and other pathways in cancer and progesteronemediated oocyte maturation. C) The top 10 enriched GO BP of the up-regulated genes. Among the 1501 up-regulated genes, there are $62 \mathrm{GO} B P$ enriched, with FDR $<0.01$. The top 10 are shown.

expressions of miR-155-5p and miR-124-3p could influence GSCs proliferation, differentiation and apoptosis, experiments with miR-155 knockdown and miR-124-3p overexpression in GSCs were conducted.
To show the effects of miR-155-5p inhibitor and miR-124-3p mimic, we used qRT-PCR to test the altered expressions of miR-155$5 p$ and miR-124-3p. Treatment with miR-155-5p inhibitor decreased the expressions of miR-155-5p, while treatment with miR-124-3p

TABLE III. The Top 10 Differently Expressed microRNA-Target Relationships

\begin{tabular}{lccc}
\hline microRNA & Gene Symbol & microRNA FC & Gene FC \\
\hline hsa-miR-198 & DCX & 2.985085 & 0.012328 \\
hsa-miR-137 & PTGS2 & 0.700126 & 0.012133 \\
hsa-miR-198 & NNAT & 4.844031 & 0.01567 \\
hsa-miR-653 & SCGN & 1.281046 & 0.019109 \\
hsa-miR-653 & GAD2 & 1.281046 & 0.02088 \\
hsa-miR-146b-5p & OTX2 & 2.377223 & 0.025847 \\
hsa-miR-152 & OTX2 & 1.738666 & 0.025847 \\
hsa-miR-653 & PEG10 & 1.281046 & 0.028099 \\
hsa-miR-125a-3p & NRXN3 & 1.996175 & 49.65864 \\
hsa-miR-653 & NRXN3 & 1.281046 & 41.06623 \\
& & & 0.029129 \\
\end{tabular}

$\theta=(|\mathrm{FC} 1-1 / \mathrm{FC} 2|)(\mathrm{FC} 1$ : upregulated gene or microRNA, FC2: the downregulated microRNA or gene, which is relative to the upregulated genes and microRNA) 

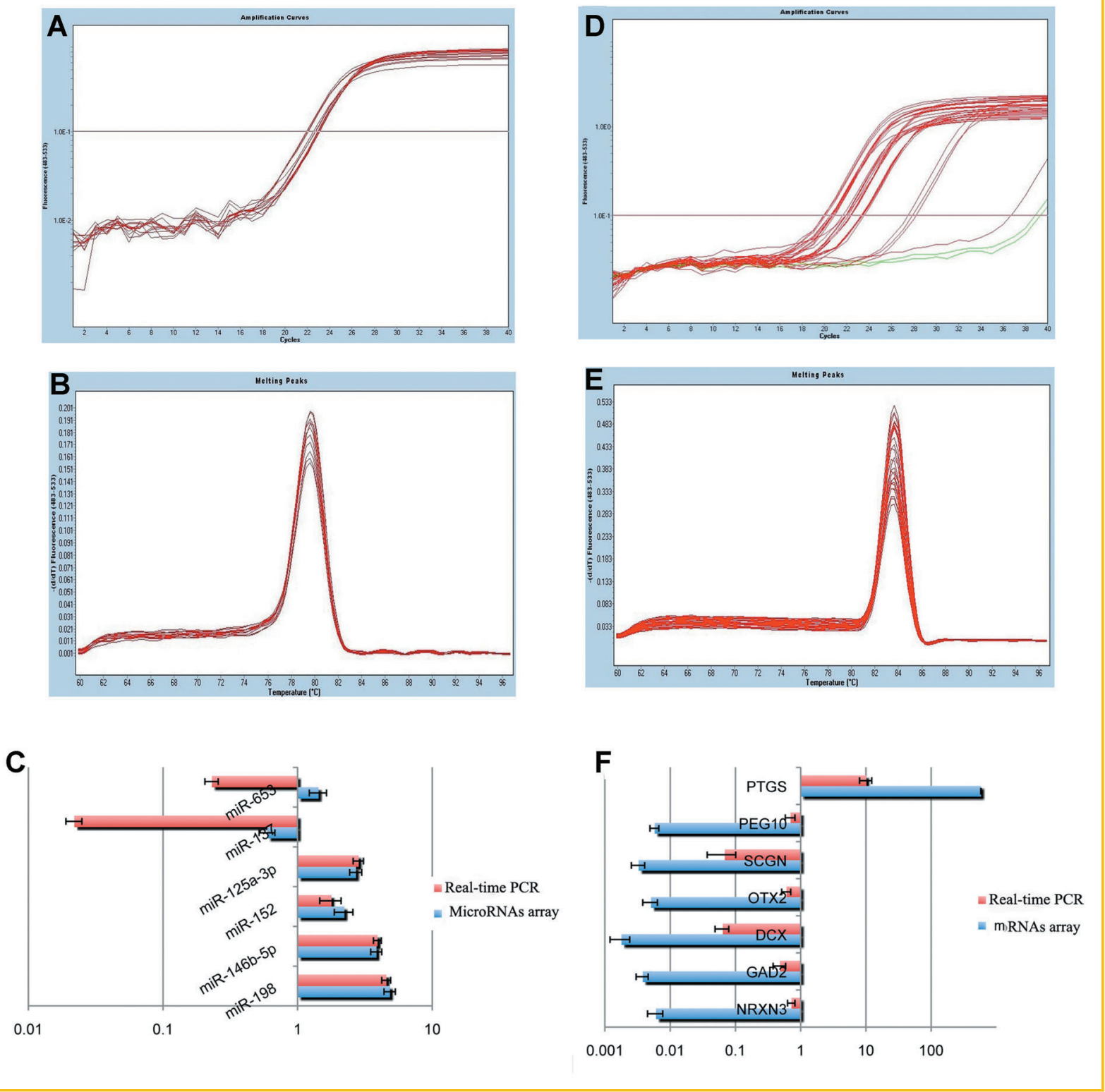

Fig. 3. Q-RT-PCR verification of miRNA and mRNA expression. The amplification curves and melting curvets in the PCR reactions were clear (A and B, D and E). C) Six miRNAs were compared between GSCs and NSCs by Q-RT-PCR. Five of the six miRNAs tested by real-time RT-PCR gave results consistent with the microarray data, except for miR-653, indicating a concordance rate of $83.33 \%$. F) Seven genes were compared between GSCs and NSCs by Q-RT-PCR. All genes tested by real-time RT-PCR gave results consistent with the microarray data, indicating a concordance rate of $100 \%$.

mimic increased the expression of miR-124-3p significantly compared to the treatment with negative controls (Fig. 5).

For function analysis, the effects of miR-155-5p and miR-124-3p were assessed by experiments with CCK-8 assay, GFAP immunoblotting and Annexin $\mathrm{V}$ staining. The results showed that both miR-155 inhibitor and miR-124-3p mimic were able to reduce the proliferation of GSCs significantly (Fig. 6). However, increased expression of GFAP was observed after miR-155-5p inhibitor treatment (Fig. 7), whereas, an increased number of Annexin V-FITC positive cells was observed in the group of miR-124-3p mimic treatment (Fig. 8). Collectively, these data suggest that miR-155-5p has a potential promoting role while miR-124-3p has an inhibiting role in the malignant development of GBM derived stem cell-like cells.

\section{DISCUSSION AND CONCLUSIONS}

Recent studies have shown that glioma may arise from GSCs that result from transformed NSCs [Bachoo et al., 2002; Alcantara et al., 2009; Holland et al., 1998]. Several studies have examined the expressions, targets and functional effects of selected miRNAs in 


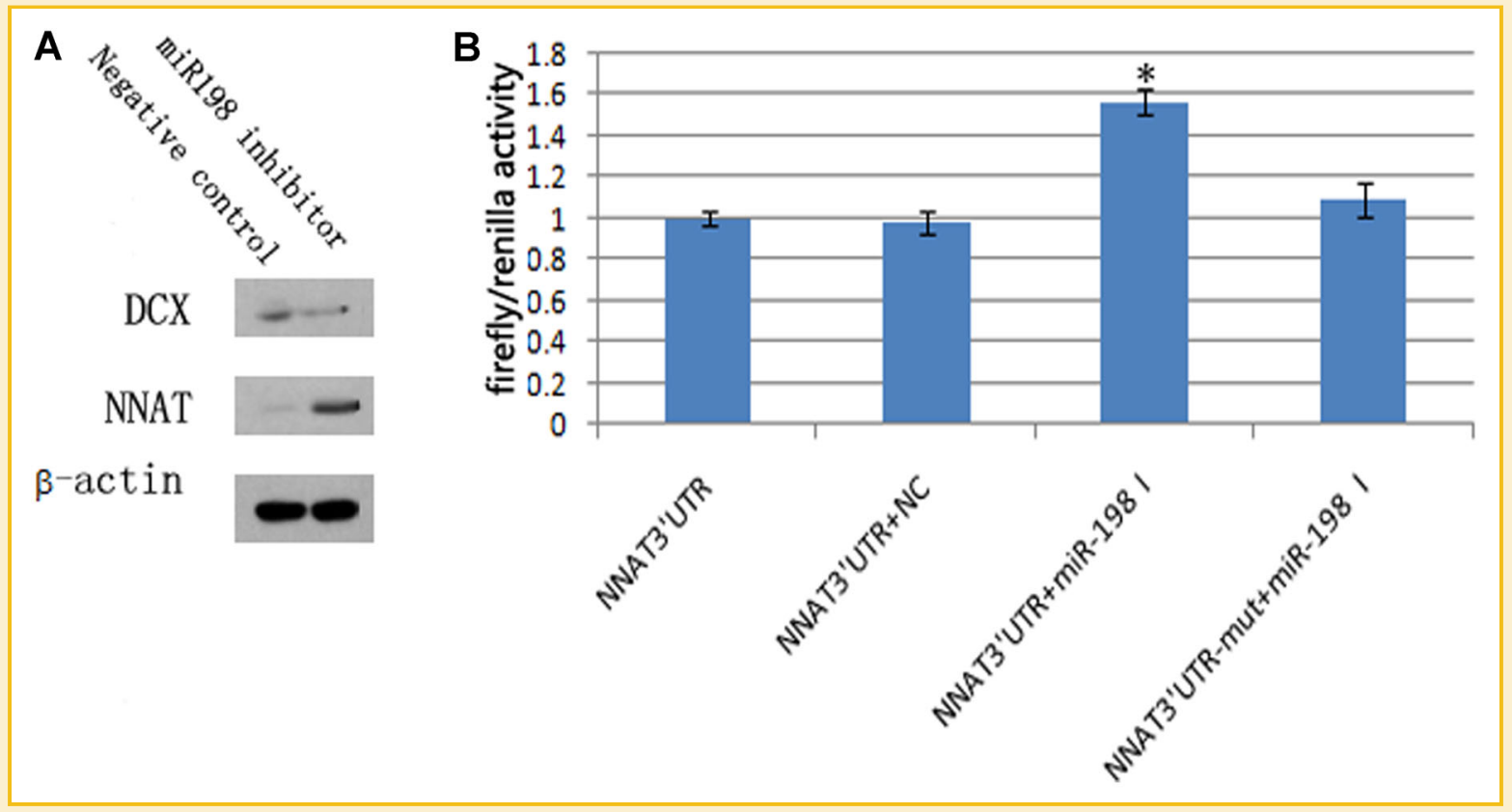

Fig. 4. Effects of miR-198 on expressions of DCX and NNAT. A) Western blot analysis showed that the expression levels of NNAT protein in the miR-198 inhibitor (miR-198 I)treated group was significantly higher than in the control. B) miR-198 I increased the luciferase activity of a reporter containing the $3^{\prime}$ UTR of NNAT $(P<0.001)$, whereas miR198 could not increase the luciferase activity of the same reporter containing a mutated sequence of $3^{\prime}$ UTR of NNAT.

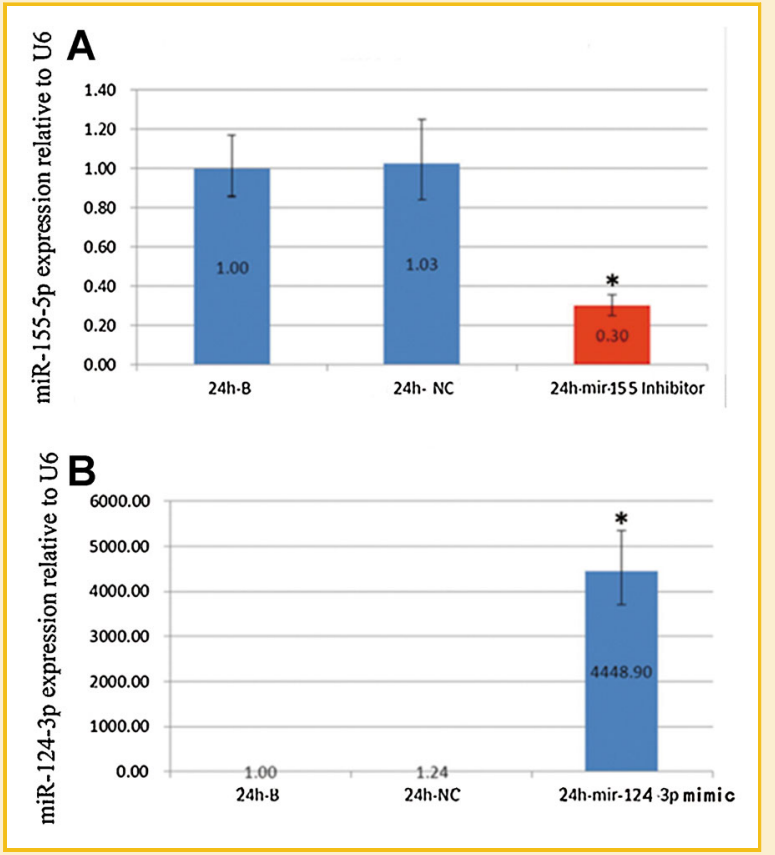

Fig. 5. miR-155-5p and miR-124-3p expressions after treatment with negative controls (NC), miR-155-5p inhibitor or miR-124-3p mimic in GSCs analyzed by qRT-PCR. A) MiR-155-5p expression in miR-155-5p inhibitor treated cells was significantly lower than in untreated cells $(24 \mathrm{~h}-\mathrm{B}$, blank control) and negative control treated cells $(24 \mathrm{~h}-\mathrm{NC}$, negative control) ( $\left.{ }^{*} P<0.05\right)$. B) MiR-124-3p expression in miR-124-3p mimic treated GSCs was significantly higher than in untreated cells $(24 \mathrm{~h}-\mathrm{B})$ and negative control treat cells $(24 \mathrm{~h}-\mathrm{NC})\left({ }^{*} P<0.01\right)$. The results are the mean \pm SD of triplicate experiments. glioma cells and tissues [Wang et al., 2012; Yu et al., 2012]. However, the differences between GSCs and NSCs in expression profiles of miRNAs and mRNAs have not been fully identified. In this study, we conducted a global analysis of both miRNA and mRNA expression in human GSCs and NSCs, and further analyzed the miRNA data and its matching mRNA data jointly for the first time. Taking a systematic approach to joint analysis will enhance our understanding of the role of miRNA in glioma pathogenesis and progression. In this report, 178 miRNAs were shown to have distinct expressions in GSCs vs. in NSCs, and 2873 mRNA expressions were altered significantly in GSCs compared to those in NSCs (Table S-2). In screening the relationships of miRNAs and mRNA targets, we obtained 947 relationships, involving 29 miRNAs and 844 protein-coding genes (Table S-3), and identified the top 10 differently expressed miRNAtarget relationships using $\theta$ value (Table III). The results of Table III showed that miR-198 is significantly upregulated in GSCs, and has higher $\theta$ values with its target genes (DCX and NNAT). Recently, miR198 was found overexpressed in esophageal cancer (Qi et al., 2013). Furthermore, the direct target genes of miR-198 were validated by western blot and luciferase activity assay. Though both DCX and NNAT were predicted as target genes of miR-198, our results of western blot and luciferase activity assay showed that NNAT, but not DCX, is the direct target gene of miR-198 (Fig. 4A \& 4B). Recent evidence indicated that NNAT expresses in GSCs and is associated with significant increase in cellular proliferation (Xu et al., 2012). In addition, Among the top 10 differently expressed miRNA-target relationships, miR-653, miR-146b-5p, miR-152, miR-155-5p, miR$125 a-3 p$ and miR-198 were found to be negatively correlate to their targeting mRNA, such as PDGF, STAT3, PTEN and OLG [Zhu et al., 2005; Kesari et al., 2006; Zheng et al., 2008; Sherry et al., 


\section{A Effect of mir-155-5p on GSC proliferation}

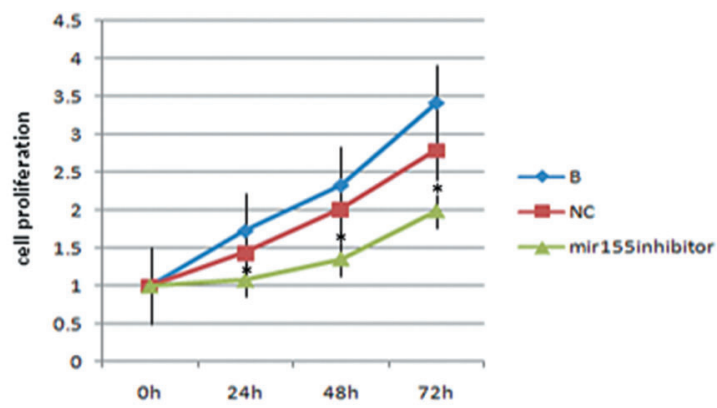

B Effect of mir-124-3p on GSC proliferation

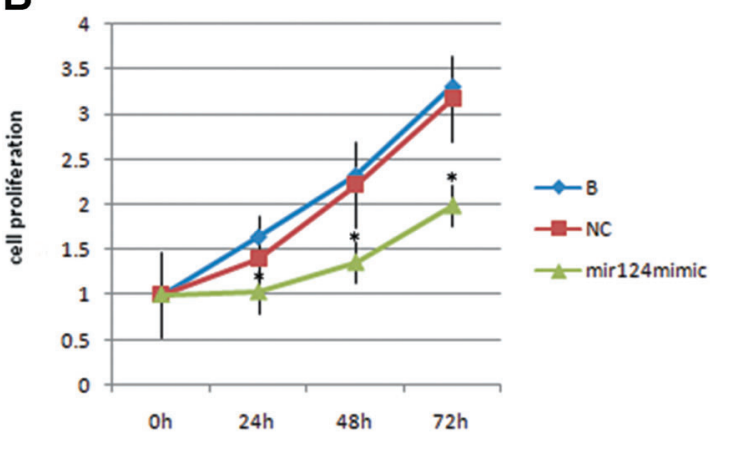

Fig. 6. The effect of miR-155-5p and miR-124-3p on the proliferation of GSCs. Both miR155 knockdown and miR-124 overexpression significantly reduced the proliferation of GSCs in vitro measured by CCK8 assay (A \& B). Cell growth was monitored every $24 \mathrm{~h}$. Absorbance at $0 \mathrm{~h}$ was assigned a value of 1. B: blank control (untreated cells), NC: negative controls. The results are the mean \pm SD of three replicates. ${ }^{*} P<0.01$.
2009], which are important stem cell regulators (Table S-3). HsamiR-125a-3p, hsa-miR-152 and hsa-miR-198 showed an association with cell cycle genes, such as CDKN2B, PTEN, PIDD and DLGAP5; whereas hsa-miR-146b-5p and hsa-miR-152 also showed an association with cell adhesion genes, such as CADM2 and NCAM1 (Table S-3). A major shift in the cell cycle rate, cell apoptosis and cell adhesion is required for the transformation from NSCs to rapid cycling and highly invasive GSCs, so these miRNAs are important in the malignant transformation from NSCs to GSCs and the predicted miRNA-target relationships may provide useful information for further studies of origin and development of glioma.

Furthermore, the functional enrichment analysis of each differential expressed miRNAs between GSCs and NSCs was undertaken using GO and KEGG software online. A set of associated miRNAs (miR-1, miR-30e-5p, miR-107, miR-129-5p, miR-137, miR153, miR-198, miR-199b-5p, miR-361-5p, miR-496, miR-128, miR$125 a-3 p$, miR-146b-5p and miR-152) were identified in this study, whose target genes were found to have at least one functional enrichment, such as cell cycle, axon guidance, adhesion junction, MAPK signaling, and wnt signaling (Table S-2). Among them, miR128 , which was found to be significantly down-regulated in GSCs, was reported to regulate oncogenic transformation and stem celllike behavior in immortalized nontumorigenic mammary epithelial cells partly by regulating the PI3K/AKT and STAT3 signaling pathways [Peng et al., 2012]. MiR-125a-3p, which was found to be significantly higher in GSCs than in NSCs, was reported to regulate the migration and invasion of tumors by mediating CCL, IGF-2 and wnt signaling [Lili et al., 2010; Alhua et al., 2012]. Both miR-146b$5 p$ and miR-152 are significantly higher in GSCs than in NSCs, and have been found to take part in cell adhesion and regulate glioma cell invasion and angiogenesis by attenuating the expression of MMP-3 [Katakowski et al., 2010]. It is likely that some of the programs that

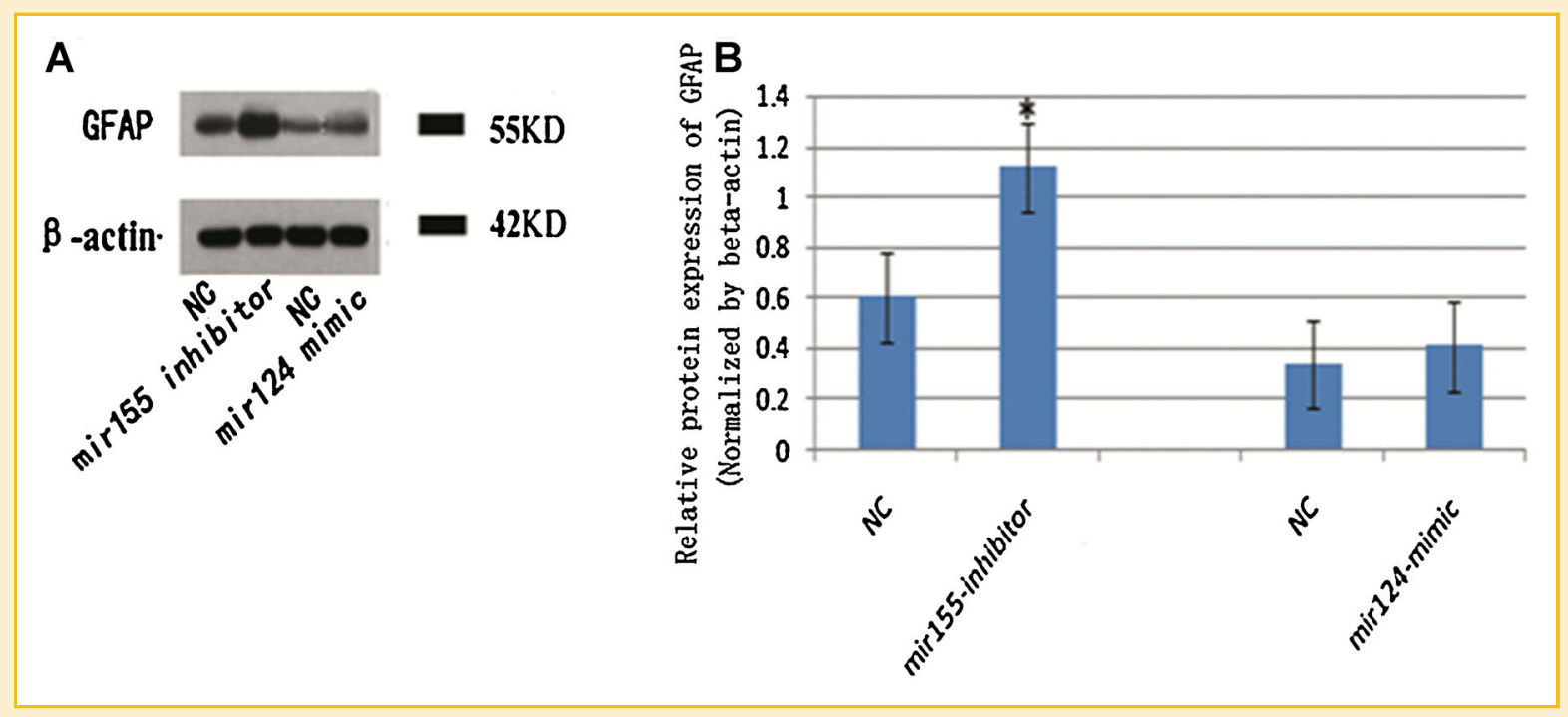

Fig. 7. The effect of miR-155-5p and miR-124-3p on the differentiation of GSCs. A) The expression of GFAP increased significantly in GSCs $48 \mathrm{~h}$ after treatment with miR-155 inhibitor detected by Western blot, while the expression of GFAP revealed no obvious changes after miR-124 mimic treatment. B) The semi-quantitative analysis of GFAP expression. NC: negative controls. The results are the mean \pm SD of three replicates. ${ }^{*} P<0.01$. 


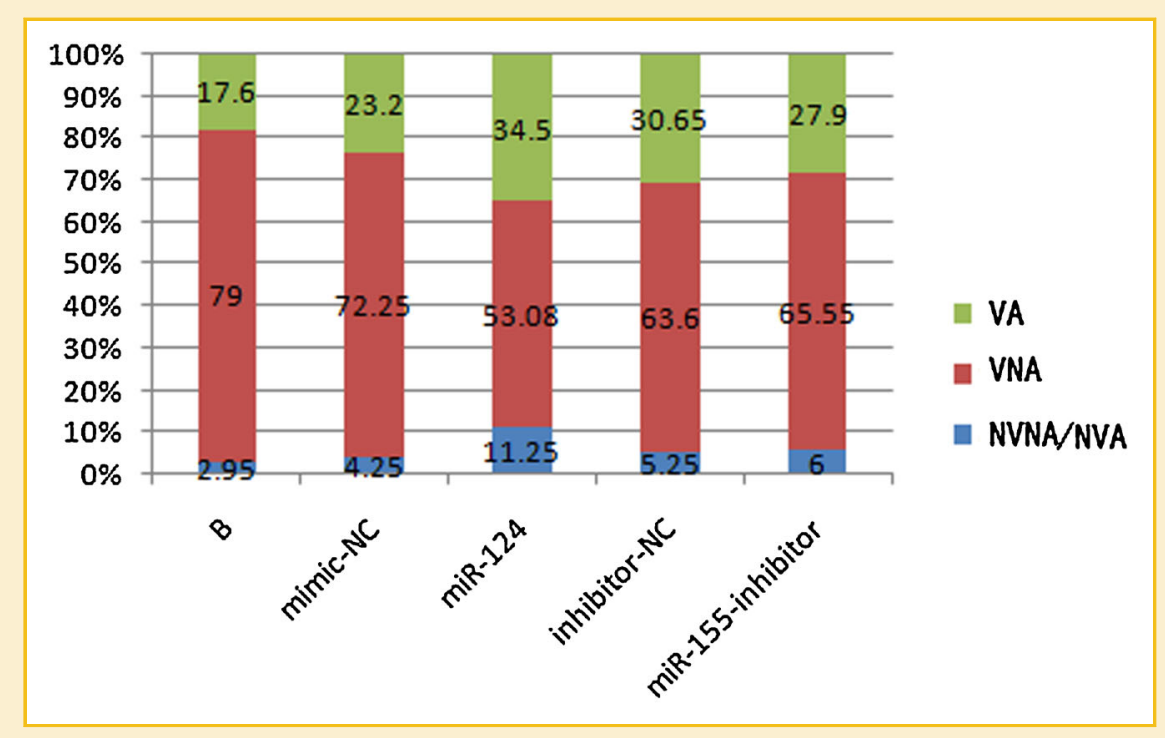

Fig. 8. The effect of miR-155-5p and miR-124-3p on the apoptosis of GSCs. Statistical analysis of the percentages of viable apoptotic cell (VA), viable non-apoptotic cell (VNA), non-viable non-apoptotic cell (NVNA) or non-viable apoptotic cell (NVA). B: blank control (untreated cells), NC: negative controls.

regulated by these miRNAs are associated with the transition from NSCs to GSCs. These miRNAs and their target genes that differentially expressed between GSCs and NSCs may represent important candidates for further characterization of the pathogenesis and development of glioma.

In addition, among 178 miRNAs, the expressions of miRNA-155$5 p$ and miRNA-124-3p were found to be altered most noticeably, so these two miRNAs were selected for functional analyses. We found that miR-155-5p could induce differentiation and inhibit proliferation of GSCs, whereas miR-124-3p could promote apoptosis and growth rest of GSCs (Figs, 6, 7, 8 5). These functional studies of miRNAs provide direct evidence that miR-155-5p and miR-124-3p, which demonstrated significant abnormal expressions in GSCs compared to NSCs, can modulate GSCs biological behaviors. These results support the conclusion that miR-155-5p plays a promoting role, whereas miR-124-3p plays an inhibitory role in the malignant transformation from NSCs to GSCs. Lang et al. compared the microRNA profile between GSCs and NSCs and also found that the expression of miR-124 significantly decreased and the expression of miR-193a-3p increased in GSCs compared to NSCs. However, they did not conduct global analysis of mRNA expression in human GSCs and NSCs and did not further characterize the functional roles of these miRNAs in GSCs [Lang et al., 2012]. In this study, we found that the expression of miR-155-5p in GSCs was nine times higher than its expression in NSCs, and miR-147 and miR-124-3p were significantly lower in GSC than in NSC. These results suggested that these miRNAs might play important roles in the transition process of NSCs to GSCs. Bioinformation analysis showed that one of the predicted targets for miRNA-155-5p is bone morphogenetic protein (BMP). Interestingly, it has been shown that BMPs could regulate the proliferation and differentiation of GSCs in several previous studies [Piccirillo et al., 2006; Lee et al., 2008]. Furthermore, Qinyan et al. reported that miR-155 targets the $3^{\prime}$ untranslated region (3'-UTR) of multiple components of the BMP signaling cascade, and results in the inhibition of BMP-mediated induction of $\mathrm{p} 21$, and reverses BMPmediated cell growth inhibition [Qinyan et al., 2010]. We also found in our previous study [Liu et al., 2009] that the BMP signaling pathway could regulate the differentiation and proliferation of malignant glioma cells. In contrast, MiR-147 has been identified as a novel tumor suppressor that co-targets EGFR-driven cell cycle network proteins and inhibits cell-cycle progression and proliferation in breast cancer [Geraldo et al., 2012]. The reduced expression of miR-124 in GSCs is also consistent with its inhibitory function in the development of many tumors. Silber reported that miR-124 inhibits the expression of CDK6 and prevents the proliferation of glioblastoma and medulloblastoma cells in vitro [Silber et al., 2013]. Together, our findings in this report may provide additional information regarding the roles played by the miRNAs in the origin and development of glioma.

Among the 2873 mRNAs, the Nicotinamide N-methyltransferase (NNMT) was observed to be significantly higher in GSCs than in NSCs in this study. NNMT has shown a very high level of expression in other cancer cell lines, and the knockdown of NNMT could efficiently suppress cell proliferation and decrease colony formation [Pozzi et al., 2011]. So, the aberrant increase of NNMT in GSCs may also be associated with GSCs development. In contrast, SRY (Sex determining region Y)-box1(Sox1) was found to be significantly lower in GSCs than in NSCs. In this study, such factor as sex should not be considered because both human GSCs and human NSCs were derived from male patients, so, the deletion or decrease of Sox 1 in GSCs may contribute to the malignant transition of NSCs to GSCs. Sox 1 has been reported to be frequently down-regulated through promoter hypermethylation in hepatocellular carcinoma (HCC) cells and tissues. The over-expression of Sox1 could suppress cell proliferation, colony formation, and invasion ability in HCC cell lines [Tsao et al., 2012]. 
It is of note that the expressional alterations of some miRNAs and mRNAs and their function roles are found contrary to their functional roles reported in some previous studies. MiR-210 was significantly lower in GSCs than in NSCs, which is at odds with its survival promotion effects in mesenchymal stem cell (MSCs) [Yu et al., 2011]. In addition, the insulin-like factor binding protein-3 (IGFBP3), which was found noticeably increased in GSCs, has been reported to be a multi-functional protein that is known to induce apoptosis of various cancer cells by the activation of caspases and the induction of cell cycle arrest [Wu et al., 2013]. These observations suggest that the same miRNA and mRNA can have distinctly different biological activities under different cellular contexts. Although some miRNAs and genes have been studied in other cancer cells previously, none of them has been studied in glioma. Thus, they should be further characterized for their regulatory roles in various aspects of GSC biology.

In summary, this study revealed broad differences in miRNA profiles between human GSCs and NSCs. Our results strongly suggest that miRNA-controlled post-transcriptional programs modulate extensive networks that define the functional properties of the transition of NSCs to GSCs. Global miRNA and mRNA expression profiles may distinguish between normal NSCs and GSCs and help with the discovery of the origin and development of glioblastoma. Clinically, these miRNAs may serve as therapeutic targets and diagnostic and prognostic tools for the management of malignant gliomas.

\section{ACKNOWLEDGMENTS}

We are grateful to Dr. Xingyi Hang and Dr. Zhiwei He for their excellent bioinformational assistance.

\section{REFERENCES}

Aihua Gong, Suyun Huang.. 2012. FoxM1 and wnt/ß-catenin signaling in glioma stem cells. Cancer Res 72:5658-5662.

Bartel DP. 2004. MicroRNAs: Genomics, biogenesis, mechanism, and function. Cell 116:281-297.

Bartel DP. 2009. MicroRNAs: Target recognition and regulatory functions. Cell 136:215-233.

Berezikov E, Guryev V, Van de Belt J, Wienholds E, Plasterk RH, Cuppen E. 2005. Phylogenetic shadowing and computational identification of human microRNA genes. Cell 120:21-24.

Calabrese C, Poppleton H, Kocak M, Hogg TL, Fuller C, Hamner B, Oh EY, Gaber MW, Finklestein D, Allen M, Frank A, Bayazitov IT, Zakharenko SS, Gajjar A, Davidoff A, Gilbertson RJ. 2007. A perivascular niche for brain tumor stem cells. Cancer Cell 11:69-82.

Chaichana KL, Guerrero-Cazares H, Capilla-Gonzalez V, Zamora-Berridi G, Achanta P, Gonzalez-Perez 0. 2009. Intra-operatively obtained human tissue: protocols and techniques for the study of neural stem cells. J Neurosci Methods 180:116-125.

Chan XH, Nama S, Gopal F, Rizk P, Ramasamy S, Sundaram G, Ow GS, Ivshina AV, Tanavde V, Haybaeck J, Kuznetsov V, Sampath P. 2012. Targeting glioma stem cells by functional inhibition of a prosurvival oncomiR-138 in malignant gliomas. Cell Reports 27:591-602.

Croce CM. 2009. Causes and consequences of microRNA dysregulation in cancer. Nat Rev Genet 10:704-714.
Dean M, Fojo T, Bates S. 2005. Tumour stem cells and drug resistance. Nat Rev Cancer 5:275-284.

Dinorah FM, Eric Bushong A, Eugene Ke, Soda Y, Marumoto T, Singer 0, Ellisman MH. 2012. Dedifferentiation of neurons and astrocytes by oncogenes can induce glioma in mice. Science 338:1080-1084.

Friedman RC, Farh KK, Burge CB, Bartel DP. 2008. Most mammalian mRNAs are conserved targets of microRNAs. Genome Res 19:92-105.

Galli R, Binda E, Orfanelli U, Cipelletti B, Gritti A, De Vitis S, Fiocco R, Foroni C, Dimeco F, Vescovi A. 2004. Isolation and characterization of tumorigenic, stem-like neural precursors from human glioblastoma. Cancer Res 64:70117021.

Geraldo MV, Yamashita AS, Kimura ET. 2012. MicroRNA miR-146b-5p regulates signal transduction of TGF- $\beta$ by repressing SMAD4 in thyroid cancer. Oncogene 31:1910-1922.

Goljanek-Whysall K, Pais H, Rathjen T, Sweetman D, Dalmay T, Münsterberg A. 2012. Regulation of multiple target genes by miR-1 and miR-206 is pivotal for C2C12 myblast differentiation. J Cell Sci 125:3590-3600.

Hwang HW, Mendell JT. 2006. MicroRNAs in cell proliferation, cell death, and tumorigenesis. Br J Cancer 94:776-780.

Katakowski M, Zheng X, Jiang F, Rogers T, Szalad A, Chopp M. 2010. MiR146b-5p suppresses EGFR expression and reduces in vitro migration and invasion of glioma. Cancer Invest 28:1024-1030.

Katz AM, Amankulor NM, Pitter K, Helmy K, Squatrito M, Holland EC. 2012. Astrocyte-specific expression patterns associated with the PDGF-induced glioma microenvironment. PLoS One 7:e32453.DOI: 10.1371/journal. pone.0032453.

Kesari S, Stiles CD. 2006. The bad seed: PDGF receptors link adult neural progenitors to glioma stem cells. Neuron 51:151-153.

Kesari S, Stiles CD. 2006. The bad seed: PDGF receptors link adult neural progenitors to glioma stem cells. Neuron 51:151-153.

Lang MF, Yang S, Zhao C, Sun G, Mural K, Wu X, Wang J, Gao H, Brown CE, Liu X, Zhou J, Peng L, Rossi JJ, Shi Y. 2012. Genome-wide profiling identified a set of miRNAs that are differentially expressed in glioblastoma stem cells and normal neural stem cells. PLoS ONE 7:e36248.Doi: 10.1371/journal. pone. 0036248 .

Lee J, Son MJ, Woolard K, Donin NM, Li A, Cheng CH, Kotilarova S, Kotliarov Y, Walling J, Ann S, Kim M, Totonchy M, Cusack T, Ene C, Ma H, Su Q, Zenklusen JC, Zhang W, Maric D, Fine HA. 2008. Epigenetic-mediated dysfunction of the bone morphogenetic protein pathway inhibits differentiation of glioblastoma-initiating cells. Cancer cell 13:69-80.

Leone PE, González MB, Elosua C, Gomez-Moreta JA, Lumbreras E, Robledo C, Santos-Briz A, Valero JM, de la Guardia RD, Gutierrez NC, Hemandez JM, Garcia JL. 2012. Integration of global spectral karyotyping, CGH arrays, and expression arrays reveals important genes in the pathogenesis of glioblastoma multiforme. Ann Surg Oncol 19:2367-2379.

Lili Jiang, Qin Huang, Siyang Zhang, Zhang Q, Chang J, Qiu X, Wang E. 2010. Hsa-miR-125a-3p and hsa-125a-5p are downregulated in non-small cell lung cancer and have inverse effects on invasion and migration of lung cancer cells. BMC Cancer 10:318-321.

Lim LP, Lau NC, Garrett-Engele P, Grimson A, Schelter JM, Castle J, Bartel DP, Linsley PS, Johnson JM. 2005. Microarray analysis shows that some microRNAs downregulate large numbers of target mRNA. Nature 433:769-773.

Maher EA, Furnari FB, Bachoo RM, Rowitch DH, Louis DN, Cavvenee WK, DePinho RA. 2001. Malignant glioma: genetics and biology of a grave matter. Genes Dev 15:1311-1333.

Piccirillo SGM, Reynolds BA, Zanetti N, Lamorte G, Binda E, Broggi G, Brem H, Olivi A, Dimeco F, Vescovi AL. 2006. Bone morphogenetic proteins inhibit the tumorigenic potential of human brain tumour-initiating cells. Nature 444:761-765.

PengXu Qian, Arindam Banerjee, ZhengSheng Wu, Zhang X, Wang $\mathrm{H}$, Pandey V, Zhang WJ, Lv XF, Tan S, Lobie PE, Zhu T. 2012. Loss of SNAIL 
regulated miR-128-2 on chromosome $3 p 22.3$ targets multiple stem cell factors to promote transformation of mammary epithelial cells. Cancer Res 72:6036-6050.

Piccirillo SG, Reynolds BA, Zanetti N, Lamorte G, Binda E, Broggi G, Brem H, Olivi A, Dimeco F, Vescovi AL. 2006. Bone morphogenetic proteins inhibit the tumorigenic potential of human brain tumour-initiating cells. Nature 444:761-765.

Pozzi V, Mazzotta M, Lo Muzio L, Sartlni D, Santarelli A, Renzi E, Rocchetti R, Tomasetti M, Ciavarella D, Emanuelli M. 2011. Inhibiting proliferation in KB cancer cell by RNA interference-mediated knockdown of nicotinamide N-Methyltransferase expression. Int J Immunopathol Pharmacol 24:69-77.

Pragathi A, Neda ISR, Alfredo QH. 2010. Gliomagenesis and the use of neural stem cells in brain tumor treatment. Anticancer Agents Med Chem 10:121-130.

Qi B, Yao WJ, Zhao BS, Qin XG, Wang Y, Wang WJ, Wang TY, Liu SG, Li HC. 2013. Involvement of microRNA-198 overexpression in the poor prognosis of esophageal cancer. Asian Pac J Cancer Prev 14:5073-5076.

Qinyan Y, Xia W, Claire F, Cameron J, Zhu H, Baddoo M, Lin Z, Flemington EK. 2010. MicroRNA MiR-155 inhibits bone morphogenetic protein (BMP) signaling and BMP-mediated Epstein-barr virus reactivation. J Virol 84:6318-6327.

Quinones-Hinojosa A, Chaichana K. 2007. The human subventricular zone: a source of new cells and a potential source of brain tumors. Exp Neurol 205:313-324.

Rich JN. 2007. Cancer stem cells in radiation resistance. Cancer Res 67:89808984.

Sherry MM, Reeves A, Wu JK, Cochran BH. 2009. STAT3 is required for proliferation and maintenance of multipotency in glioblastoma stem cells. Stem Cells 27:2383-2392.

Shuang L, Feng Y, Wen-hong F, Shuwei W, Guoxin R, Jianning Z, Zengmin T, Ming F. 2012. Over-expression of BMPR-IB reduces the malignancy of glioblastoma cells by upregulation of p 21 and p27Kip1. J Exp Clin Cancer Res. DOI:10.1186/17569966-3152.

Shuang L, Zengmin T, Feng Y, Quanjun Z, Ming F. 2009. Generation of dopaminergic neurons from human fetal mesencephalic progenitors after coculture with striatal-conditioned media and exposure to lowered oxygen. Brain Res Bull 80:62-68.

Silber J, Hashizume R, Felix T, Hariono S, Yu M, Berger MS, et al. 2013. Expression of miR-124 inhibits growth of medulloblastoma cells. Neuro Oncol 15:83-90.
Silber J, Lim DA, Petrisch C, Persson AI, Maunakea AK, Yu M, Vandenberg SR, Ginzinger DG, James CD, Costello JF, Bergers G, Weiss WA, AlvarezBuylla A, Hodgson G. 2008. MiR-124 and miR-137 inhibit proliferation of glioblastoma multiforme cells and induce differentiation of brain tumor stem cells. BMC Medicine 24:6-14.

Singh SK, Hawkins C, Clarke ID, Squire JA, Bayani J, Hide T, Henkelman RM, Cusimano MD, Dirks PB. 2004. Identification of human brain tumour initiating cells. Nature 432:396-401.

Wang Q, Li P, Li A, Jiang W, Wang H, Wang J, Xie K. 2012. Plasma specific miRNAs as predictive biomarkers for diagnosis and prognosis of glioma. J Exp Clin Res.

Wu C, Liu X, Wang Y, Tian H, Xie Y, Li Q, Zhang X, Liu F. 2013. Insulin-like factor binding protein-3 promotes the $\mathrm{G} 1$ cell cycle arrest in several cancer cell lines. Gene 512:127-133.

Xu DS, Yang C, Proescholdt M, Brundl E, Brawanski A, Fang X, Lee CS, Well RJ, Zhuang Z, Lonser RR. 2012. Neuronatin in a subset of glioblastoma multiforme tumor progenitor cells is associated with increased cell proliferation and shorter patient survival. PLoS One 7:e37811.Doi: 10.1371/journal.pone.0037811.

Ying Zhang, Anindya Dutta, Roger Abounader.. 2012. The role of microRNAs in glioma initiation and progression. Front Biosci 17:700-712.

Yu J, Cai X, He J, Zhao W, Wang Q, Liu B. 2012. 2012. Microarray-based analysis of gene regulation by transcription factors and microRNAs in glioma. Neurol Sci.

Yu N, Bian-Mei H, Xue-Bin L, Yang JJ, Wang F, Cong XF, Chen X. 2011. Identification of microRNAs involved in hypoxia- and serum deprivationinduced apoptosis in mesenchymal stem cells. Intern J Biol Sci 7:762-768.

Zheng H, Ying H, Yan H, Kimmelman AC, Hiler DJ, Chen AJ, DePinho RA. 2008. P53 and Pten control neural and glioma stem/progenitor cell renewal and differentiation. Nature 455:1129-1133.

Zhu Y, Guignard F, Zhao D, Liu L, Burns DK, Mason RP, Messing A, Parada LF. 2005. Early inactivation of p53 tumor suppressor gene cooperating with NF1 loss induces malignant astrocytoma. Cancer Cell 8:119-130.

\section{SUPPORTING INFORMATION}

Additional supporting information may be found in the online version of this article at the publisher's web-site. 